\title{
PAMETNI GRADOVI KAO DEO DIGITALNE EKONOMIJE
}

\author{
Radmila Živković, \\ Ivana Brdar*, \\ Jelena Gajić, \\ Katarina Čkonjević
}

Univerzitet Singidunum, Beograd, Srbija

Odgovorno lice:

Ivana Brdar

e-pošta:

ibrdar@singidunum.ac.rs
Rezime:

Uvođenje informacionih tehnologija i unapređenje komunikacije su dve najznačajnije karakteristike digitalizacije koje su dovele do razvoja pametnih ekonomija, pametnih gradova, država, i lokalnih samouprava. Države, gradovi, lokalne samouprave, popularne turističke destinacije suočavaju se različitim izazovima, koristeći prednosti digitalizacije i marketinške kampanje kako za razvoj tako i za bolje pozicioniranje u globalnom okruženju. Gradovi koji koriste sve prednosti digitalizacije su brend gradovi, pametni gradovi a intelektualni kapital, kreativnost i inovativnost su tri glavne karakteristike ovih gradova. Cilj ovog rada je da se ukaže da budući razvoj gradova zavisi od sinergije digitalne ekonomije i upravljanja pametnim gradovima.

Ključne reči:

digitalna ekonomija, pametni gradovi, ekonomija aplikacija, brendiranje gradova.

\section{UVOD}

Razvoj elektronske trgovine, ujedno i elektronskog bankarstva je doveo do razvoja i digitalne ekonomije. Prodaja i trgovina bez posrednika su danas sve više prisutni, tržišta se razvijaju, manje kompanije ulaze na nova tržišta, dolazi do razvoja novih proizvoda i vrsta usluga, i tako dalje [1].

Koncept digitalne transformacije koji koristi tehnologiju da bi se popravile performanse, u novom veku, zaslužuje mnogo više pažnje [2].

Ekonomija, koja se temelji na komunikaciji, tehnologiji i upravljanju znanjem će biti uspešna i ako se koncentriše na racionalnu, odnosno na efikasnu i efektivnu upotrebu znanja kao jednog od najvažnijeg nematerijalnog resursa kako u proizvodnim, tako i u uslužnim delatnostima. Uslov za realizaciju strategiju ekonomskog i privrednog razvoja predstavlja korišćenje znanja [3].

\section{EKONOMIJAAPLIKACIJA}

$\mathrm{Na}$ početku, niko nije mogao da zna kolika će, zapravo, biti app ekonomija. Apple nudi korisnicima veliki izbor softvera u odnosu na druge rivale; BlackBerry je pravio velike „korake“ progresije; Već 
formirani giganti - Nokia i Microsoft su imali poteškoće da prate nove trendove. Kompanije zarađuju tako što prodaju aplikacije, od reklama van aplikacije, kao i prodajući digitalne usluge putem aplikacija [4]. ICT navodi da ,app ekonomija predstavlja zbir svih ekonomskih aktivnosti, proizvode i usluge, koji se prikazuju putem aplikacija korisnicima mobilnih telefona i uređaja" [5]. Pojam „App“ je skraćenica koja se odnosi na aplikacije na kompjuterskoj platformi [6].

Tržište aplikacija je počelo sa razvojem 2010. godine kada je došlo do kreiranja aplikacija na mobilnim telefonima koje su pokrenute od strane kompanije Apple (Apple App Store) i Google (Google Play). Od tada je došlo do porasta korišćenja „pametnih“ telefona, Interneta i ekonomija aplikacija je postala važan deo svetskog tržišta. Aplikacije igraju veliku ulogu u raznim industrijama: turizam, trgovina, bankarstvo, industrija igrica i zabave.

Dva glavna operativna sistema za aplikacije su Google Android i Apple iOS. Apple zauzima veće tržišno učešće, međutim, Android sistemi su sve popularniji. Za razliku od Apple iOS operativnog sistema koji je zatvoren, Android operativni sistem je otvoren, što podrazumeva da korisnici mogu preuzeti aplikacije ne samo iz Google Play prodavnice, već i od drugih izvora. Kina i Japan su dva najveća tržišta koja koriste Android aplikacije, dok se iOS aplikacije najčešće koriste u Evropi, Americi, Australiji i Kanadi [7]. Iako Apple App Store prodavnica ima manje aplikacija, u odnosu na Android, navodi se da Apple prodavnica ima mnogo veće prihode u odnosu na Google Play prodavnicu, i da korisnici Apple aplikacija više provode vreme na svojim telefonima i kupuju aplikacije, u odnosu na Android korisnike. Međutim, još jedna od razlika jeste da Android aplikacije koštaju upola manje u odnosu na iOS aplikacije [7].

Danas, app ekonomija, zajedno sa digitalnom ekonomijom, je pokrenula sledeće [8]:

- Kreiranje poslova u oblasti IT-a i telekomunikacija širom sveta, a najviše na američkom i evropskog tržištu.

- Porast inovacija u oblasti IT-a koje su povezane sa razvojem pametnih telefona.

- Povećanje rasta i razvoja države i pomoć nerazvijenim državama sveta.

Ekonomski značaj app ekonomije je vidljiv svuda, ali je teško odrediti veličinu app ekonomskog tržišta. Kompanija App Ann definiše app ekonomiju kao ,svako ko zarađuje novac i ima posao zahvaljući mobilnim aplikacijama"i očekuje se, do 2020. godine da će app ekonomija dostići veličinu od \$101 milijardi. App prostor najviše zauzimaju sledeće aplikacije WhatsApp (dostigao više od 1.2 milijardi korisnika u januaru 2017. godine, što je više od 700 miliona u januaru 2015. godine); Facebook je platforma koja ima svoja posebna prava i Messenger usluge, koje su do jula 2016. godine imali više od 1 milion aktivnih korisnika; WeChat, komunikacijska platforma popularna u Kini koja je 2016. godine imali više od 846 miliona korisnika [5].

Uloga app ekonomije u ekonomskom razvoju ogleda se u generisanju prihoda, povećanju zaposlenosti i kreiranju mladih, talentovanih zaposlenih u oblasti IT-a, mogućnosti da se aplikacije instaliraju u bilo kom delu sveta, app kompanije mogu da funkcionišu kao tradicionalne kompanije itd. [9].

Mikro, mala i srednja preduzeća širom sveta dominiraju na tržištu app ekonomije u oblasti aplikacija na mobilnih telefonima. App Store predstavlja idealnu platformu za poslovanje za mikro, mala i srednja preduzeća, jer veličina preduzeća omogućava brzo reagovanje na promene i na adaptacije koje digitalizacija donosi. Autori Godfrey, Bernard i Miller navode da 82\% mikro, malih i srednjih preduzeća u Americi vode app tržište koje je idealno tržište za rast i razvoj ovih preduzeća $[10,11]$.

App ekonomija se danas, najčešće primenjuju u američkim zemljama, zemljama EU, i razvijenim azijskim zemljama. Na primer, u Koreji, app ekonomija je veoma značajna zbog porasta radnih mesta. U aprilu 2018. godine kompanija AhnLab je dala oglas u potrazi za programerom u telekomunikacionoj oblasti, a u maju 2018. godine marketinška agencija Incaco Communications je kreirala oglas za potrebom app programera. Veliki broj kompanija je početkom aprila 2018. godine širom Koreje dalo oglase u potrazi za programerima u oblasti kreiranja aplikacija za iOS i Android sisteme u turističkoj industriji, industriji zabave, automobilskoj industriji, u oblasti finansija, bankarstva i revizije, u oblasti obrazovanja, zdravstvenoj industriji i mnogim drugim industrijama [8].

Long i Mandel (2018) su analizirali Čile kao jednu od vodećih zemalja Južne Amerike i došli su do zaključka da primena app ekonomije, kao i kod Koreje najviše doprinosi otvaranju novih radnih mesta. U Čileu se najviše zapošljavaju programeri u oblasti telekomunikacionih tehnologija i u IT firmama kao što su: Baytex SA, ReignDesign, PyS Consultants, Xinergy, i tako dalje [12].

\section{Nedostaci i prednosti uvođenja app servisa}

Najznačajiniji app onlajn servisi su: Facebook, WhatsApp, Viber, Skype, Snapchat, Facetime, iMessage, 
Google Voice, LINE, Netflix i Hulu. Regulatorni problemi korišćenja aplikacija su mnogi, a neki od njih su [5]:

- Za korišćenje određenih aplikacija ne postoje ugovori već korisnici mogu, ili ne moraju da potvrde da se slažu sa uslovima korišćenja.

- Moć telekomunikacionih partnera je ograničena i ne postoji mogućnost ulaska investitora na app tržište.

- Onlajn provajderi usluga mogu, i ne moraju da plaćaju porez.

- Rast Internet tržišta je sve veći i ne postoji specifična zakonska regulativa.

- Klasifikacija onlajn sadržaja nije regulisana zakonskom regulativom.

Korišćenje aplikacije je jedna od najznačajnijih strategija mobilnih operatera, što nas navodi da zaključimo sledeće:

- Mobilne aplikacije grade lojalnost među potrošačima - Mobilne aplikacije su kreirane tako da odgovaraju svim profilima ljudi koji rade u raznim delatnostima. Sem toga, aplikacije se redovno ažuriraju, a korisnici se redovno obaveštavaju o novinama i aktuelnostima, što dovodi do njihove lojalnosti korišćenja određene aplikacije.

- Mobilne aplikacije funkcionišu kao „ekvalajzeri“, nebitno kakav im je kontekst - Nebitno koliko ljudi koristi aplikaciju, koliko su motivisani i koliko godina imaju, istraživanja pokazuju da svi koriste aplikacije na svojim ,pametnim“ telefonima, i provode veliki broj vremena koristeći razne aplikacije. Istraživanja pokazuju da $92 \%$ Internet korisnika najviše vremena provodi upravo na aplikacijama.

- „Sve u jednom“ hardver omogućava da je sve moguće - Internet korisnici mogu koristiti razne vrste aplikacije za različite svrhe. Svaka aplikacije je specijalizovana za određeni softver, što omogućava korisnicima da koriste razne vrste aplikacija $\mathrm{u}$ isto vreme.

Kompanije koje se smatraju najvećim inovatorima aplikacija u Americi su: Aces Health, Bit Source, Convoy, Digi Smart Temps, Fooji, Helix, Lavu, MelviCorp, One Drop, Passport, Soteria, System, Tome, UMMC, Vital Herd, WalkSmart, i tako dalje [12].

Najveći izazov u budućnosti biće bezbednost podataka. Tehnološke kompanije i IT stručnjaci će morati da unaprede sistem zaštite podataka, međutim, rizik će uvek postojati. Inovacije u app ekonomiji će se odnositi na kreiranje novih platformi za interakciju sa zdravstvenim ustanovama, finansijskim institucijama, finansijske transakcije će biti unapređenje, HR menadžeri će moći da kreiraju ugovore putem onlajn aplikacije, čak će se i dozvole za parking digitalizovati. Sa novim mogućnostima koje app ekonomija donosi, pacijenti će moći da pregledaju svoju podatke putem aplikacija i imati kontakt sa osiguravajućim kompanijama. Kompanije će imati svoje aplikacije, putem koje će potrošači moći da dobiju određene informacije i vrše novčane transakcije, i tako dalje.

\section{PAMETNI GRADOVI KAO DEO DIGITALNE EKONOMIJE}

Pametni gradovi su se počeli pominjati još osamdesetih godina prošlog veka, a pametan grad je onaj koji koristi svoje resurse maksimalno. To podrazumeva da je ekonomija digitalna, pametna okolina, podrazumeva pametnu vlast i pametne ljude. Inovacije, produktivnost, preduzetništvo, ekonomski indikatori, fleksibilnost privrede i međunarodna saradnja sa drugim zemljama podrazumeva pametnu ekonomiju, tj. digitalnu ekonomiju. Digitalna ekonomija je jedan od uslova da grad postane brend grad. Ukoliko grad koristi digitalnu ekonomiju, tada se grad razvija i raste, čime postaje brend grad i atraktivan za turiste [13].

Sem toga, brend gradovi su pristupačni na lokalnom i nacionalnom nivou sa dobro izgrađenom infrastrukturom, inovativnim i sigurnim transportnim sistemima, što takođe podrazumeva i pametni grad. Pametna okolina se odnosi na to da se grad bazira na upravljanju prirodnim resursima i vodi računa o životnoj sredini, što je takođe još jedna od odlika brend gradova. Intelektualni kapital je ono što povezuje pametni i brend grad. Pametni ljudi imaju visok nivo kvalifikacija, afinitet prema učenju, kreativni i fleksibilni [13].

Ono što je zajedničko brend i pametnim gradovima jeste sastav pametnog života. To podrazumeva da pametni, odnosno brend grad ima bogato kulturno-istorijsko nasleđe, dobre zdravstene uslove, dobar kvalitet življenja, obrazovne ustanove i tako dalje. Pametna vlast je koncipirana tako da učestvuje u donošenju odluka, nudi javne i socijalne usluge i donosi političke strategije i planove za razvoj [13].

Ne postoji tačna definicija pametnog grada. Nekoliko izveštaja i časopisa je dalo svoje predloge za tačnu definiciju. Gasco-Hernandez (2018) je definisao šest dimenzija evropskih pametnih gradova [14]:

1. Pametna ekonomija - kompetitivnost ekonomije;

2. Pametni ljudi-ljudski i društveni kapital; 
3. Pametna vlada - učestvovanje u svim ekonomskim sferama;

4. Pametna mobilnost - transport, informacione i komunikacione tehnologije;

5. Pametno okruženje - prirodni resursi i briga o životnoj sredini;

6. Pametno življenje - kvalitet života u gradu.

Gasco-Hernandez (2018) takođe smatra da postoje tri konceptualne dimenzije pametnih gradova: tehnologija (ključ transformiranja života i rada u gradu), ljudi (ljudski kapital i edukacija), i zajednica (podrška vlade i politika), zaključujući da se grad smatra pametni gradom onda kada se investira u ljudski kapital, i u IT infrastrukturu, kako bi se poboljšao život u gradovima uz pomoć Vlade [14].

\section{PRIMERI PAMETNIH GRADOVA}

Desetine digitalnih aplikacija bavi se različitim vrstama problema, poput smanjenje kriminala, bržeg protoka saobraćaja, smanjenje zdravstvenog opterećenja, izbegavanje emisije ugljen dioksida i dr. u funkciji poboljšanja kvaliteta života građana, kroz optimizaciju postojećih sistema. Alati su dostupni u više domena: bezbednost, mobilnost, zdravlje, energija, voda, otpad, ekonomski razvoj i stanovanje i angažovanje zajednice.

Bezbednost obuhvata rad policije, pametan nadzor, optimizaciju reagovanja u hitnim slučajevima, sisteme ranog upozoravanja na katastrofe, lične aplikacije za uzbunu i dr. Meksiko i Japan su uveli rane sisteme upozorenja za zemljotrese koji stanovnicima omogućava da za nekoliko minuta stignu do najsigurnijeg mesta u blizini. [18]

Smatra se da pametni gradovi mogu biti katalizatori za bolje zdravlje. Zdravstvena zaštita obuhvata telemedicinu, daljinski monitoring pacijenata, upozorenja, prvu pomoć, nadzor zaraznih bolesti, zdravlje majki i dece, informacije o kvalitetu vazduha i vode u realnom vremenu, digitalno praćenje i plaćanje odlaganja otpada i dr. Aplikacije koje pomažu u sprečavanju, lečenju imaju proaktivan i preventivan pristup lečenju, sa potencijalom da smanje zdravstveno opterećenje u gradovima za više od 4 posto. Ovi sistemi koriste digitalne uređaje za očitavanje vitalnih parametara, a zatim ih bezbedno prenose doktorima na drugoj lokaciji radi procene. Ovi podaci mogu upozoriti i pacijenta i doktora kada je potrebna rana intervencija, odlaganje komplikacija i hospitalizacija. Gradovi mogu da koriste podatke i analitiku da bi preciznije identifikovali demografske grupe sa povećanim profilima rizika i ciljanim intervencijama. Takozvane mHealth intervencije mogu da šalju poruke o vakcinacijama, sanitaciji i pridržavanju režima antiretrovirusne terapije. $U$ gradovima sa niskim primanjima sa visokom stopom smrtnosti odojčadi, intervencije zasnovane na podacima usmerene samo na zdravlje majke i deteta mogle bi se smanjiti za više od 5 posto. Gradovi u razvoju takođe mogu ostvariti smanjenje od 5 posto korišćenjem sistema za nadzor zaraznih bolesti kako bi ostali korak ispred epidemija koje se brzo razvijaju, kao što su to uradili službenici za javno zdravstvo tokom izbijanja Zike 2016. godine koje se proširilo iz Rija u Majami. [18]

Mobinost uključuje informacije o javnom prevozu u realnom vremenu, digitalno plaćanje javnog prevoza, transportnu infrastrukturu i signalizaciju, smart parkiranje, putnu navigaciju, opterećenje saobraćaja u pojedinim delovima grada. Mobilnost uključuje i digitalni poslovni porez, online programe za prekvalifikaciju, personalizovano obrazovanje, lokalne centre za e-karijeru, digitalne dozvole za upotrebu zemljišta i gradnju, katastarsku bazu podataka, Peer-to-peer platformu za smeštaj, lokalne platforme za povezivanje i druge digitalne usluge građanima i posetiocima. Barselona je kreirala Decidim digitalnu platformu za građansko učešće. Korisnicima se nudi način da se uvažavaju odluke gradskih veća, daju predlozi, učešće u diskusionim grupama o njihovim problemima i sl. Moskva je na sličan način razvila aplikaciju Active Citizen za pozivanje javnosti da direktno utiče na urbanističko planiranje i tranzitne odluke. Prateći model velikih platformi za zapošljavanje kao što su LinkedIn, Indeed $i$ Monster, gradovi poput Los Anđelesa izgradili su svoje digitalne platforme za lokalno zapošljavanje. The JobsLA Centar za e-karijeru nudi ne samo popise poslova, već i besplatne online kurseve i resurse.

Kada je energetska efikasnost u pitanju, aplikacije obuhvataju automatizaciju sistema zgrada, automatizaciju energije u stanovima, potrošnju, delimičnu cenu i sl. Sistemi omogućavaju uvid u potrošnju i kvalitet vode, kontrolu curenja, pametno navodnavanje i sl. Sa sjajnim zgradama i zelenim površinama, Južnokorejski Songdo je visoko energetski efikasan i visoko digitalan grad. Kućni otpad je direktno iz kuća prebačen kroz mrežu tunela u procesne centre za sortiranje i tretman, eliminišući potrebu za kamionima.

U Saudijskoj Arabiji je izdvojeno 500 milijardi dolara za novi urbani ekosistem na obali Crvenog mora. Konstrukcija već je počela, u prvoj fazi očekuje se da će biti završen 2025. NEOM je zamišljen kao zona nulte 
emisije, jer je bazirana na tehnologiji vetra i solarne energije. Projekat se fokusira se na to kako pametni gradovi mogu implementirati robotiku za rukovanje repetitivnim zadacima.

Gradovi koji planiraju digitalizaciju mogli bi da smanje broj smrtnih slučajeva, broj nezgoda u drumskom saobraćaju i izbijanje požara od osam do 10 procenata. Prediktivni rad policije, mapiranje kriminala i izrada sigurnosnih kućnih sistema bi takođe doprineli smanjenju mnogih neželjih pojava. U Riu de Žaneiru država je implementirala sistem za mapiranje zločina. Platforma je omogućila bolju razmenu informacija između vojske i policije smanjivši kriminal za 30\%.[18]

Pametni sistemi mogu optimizovati bezbednost u saobraćaju, a neke aplikacije koje su osmišljene mogu smanjiti vreme putovanja za zaposlene za 15-20 posto. Potencijal koji je povezan sa svakom aplikacijom je veoma promenljiv, u zavisnosti od gustine naseljenosti grada, postojeće tranzitne infrastrukture i obrazaca putovanja. U gradu kao što je Njujork, pametne tehnologije štede prosečnu dnevnu vožnju skoro 15 minuta dnevno. Prikupljanje i analiza podataka o korišćenju javnog saobraćaja takođe može pomoći gradovima da donesu bolje odluke o modifikovanju autobuskih linija, postavljanju saobraćajnih signala, dodavanju biciklističkih staza i dodeljivanju budžeta za infrastrukturu. Mnogi gradski tranzitni sistemi, poput onih u Hjustonu i Londonu, funkcionišu na bazi digitalnih platnih sistema. U bliskoj budućnosti, transport kroz London će biti takav da će za pešake biti bezbedno jer će moći da vide određene senzore vezano za dolaske vozila. Grad planira da ugradi 3D mape za turiste, i tako dalje. Evolucija Londona u proteklih nekoliko godina je i bazirana na digitalnoj tehnologiji kao što su senzori, analiza podataka i slično. Trenutno postoje pilot projekti za pametne gradove širom sveta, a tehnologija se sve više i više razvija [14]. Neki od njih idu korak dalje nudeći pretplatu na mobilnost koja pokriva više načina prevoza. Helsinki's Vhim mobilna aplikacija, na primer, naplaćuje mesečnu naknadu za neograničeno korišćenje bilo kojeg tipa javnog prevoza, plus taksi i korišćenje usluge deljenja vožnje.

Pametne aplikacije za parkiranje usmeravaju vozače direktno na dostupna mesta, elimininišući vreme kruženja po gradskim blokovima. Moskva je implementirala razne inteligentne alate za upravljanje saobraćajem, koje je kombinovala sa velikim ulaganjima u javni prevoz i nove politike parkiranja.

Pametne gradske tehnologije mogu stvoriti ili uništiti veliki broj radnih mesta. Procenjuje se da bi čitav niz pametnih gradskih tehnologija mogao imati neznatno pozitivan neto uticaj na zapošljavanje, što bi do 2025. godine dovelo do povećanja za 1 do 3 posto. Ovaj broj kombinuje direktne, indirektne i indukovane efekte posla koji potiču od nekoliko događaja. Prvo, pametne gradske tehnologije će direktno eliminisati neke poslove, kao što su administrativni i terenski poslovi u gradskoj upravi, dok stvaraju druge, kao što su održavanje, poslovi vožnje i privremeni poslovi instalacije. Drugo, centri za e-karijeru i platforme za digitalno zapošljavanje mogu imati skroman pozitivan uticaj stvaranjem efikasnijih mehanizama za zapošljavanje i privlačenje više nezaposlenih i neaktivnih ljudi u radnu snagu, sa programima prekvalifikacije. Konačno, digitalizacija vladinih funkcija kao što su izdavanje dozvola za poslovanje, izdavanje dozvola i podnošenje poreza može osloboditi lokalna preduzeća od birokratije, doprinoseći efikasnijoj poslovnoj klimi. [18]

Najpoznatiji primeri pametnih gradova su [15]:

- Dubai, Ujedinjene Arapske države - U cilju da bude domaćin World Expo 2020. Dubai je inspirisan da kreira „Internet of Everything“ zajedno sa kompanijom Cisco i drugim IT kompanijama koji povezuju ljude putem WI-Fi i real time interaktivnh gradova u sektorima infrastrukture, podzemnog transporta, javne bezbednosti, i turizma.

- Meksiko, Meksiko Siti - Meksiko je pionir u pametnim gradovima u Latinskoj Americi koji koristi digitalnu vladu kako bi se napravili programi pročišćenja vazduha, gde će se koristiti bicikle i određeni programi korišćenja automobila, kao i promocija pametnih i zelenih infrastruktura. Meksiko je jedan od prvih gradova koji je koristio tehnologiju za apsorpciju smoga.

- Songdo, Južna Koreja - Songdo je prvi specijalizovano dizajniran pametni grad u kojem je sve digitalizovano. Zgrade imaju automatsku kontrolu klime i ulaz je kompjuterizovan, sve što se koristi je digitalno i koristi se u cilju očuvanja životne sredine.

- Singapur - Singapur je takođe jedan od gradova koji je počeo da koristi tehnologiju u svrhu zaštite životne sredine. U 2014. godini grad je lansirao Smart Nation program kao viziju koju će grad moći da vidi baziranu na naprednoj tehnologiji koja će postići ekonomski rast i bolji kvalitet života u Singapuru. Singapur želi da privuče što više kompanija kako bi testirali tehnologiju na ostrvu. Singapur ima jako dobru IT infrastrukturu, populacija je visoko obrazovana, i vlada se 
sve više zalaže za digitalnu ekonomiju. Najveći izazov u ovom gradu je mobilnost jer populacija raste iz dana u dan. Redukovanje broja putovanja širom zemlje je veliki cilj vlade Singuapura. Vlada Singuapura je uvek otvorena za nove ideje.

- Johanesburg, Južna Afrika - Grad ima partnerstvo sa telekomunikacionim provajderom Bwired kako bi postao prvi afrički pametni grad do 2040. godine investiranjem u brzi Internet i Wi-Fi pristup, glas/video/sadržaji/protok podataka, bolja infrastruktura i korišćenje elektronskog poslovanja za vlade, edukaciju i zdravstvo.

- Barselona, Španija - Barselona je bila domaćin Smart City Expo događaja i smatra se da je ova zemlja jedna od lidera u oblasti tehnologije i primene tehnlogije. Barselona ima BCN Smart City platformu na kojoj se nalaze sve informacije vezano za ovaj grad. BCN Smart City platforma omogućava da se stavi fokus na interaktivne veb sajtove koji imaju sve detalje o pametnih gradovima, sve većem korišćenju društvenih mreža, najbolje aplikacije kako na što bolji način upoznati Barselonu i šta posetiti, OpenData BCN projekat koji daje sve neophodne informacije koje su javne, Smart City kamp, i tako dalje.

- Peking, Kina - U Kini postoji mnogo pametnih gradova, ali je Peking jedan od najvećih gradova. Ovaj grad ima plan do 2012. godine da se postigne cilj održivosti i održavanja životne sredine. Zagađenje vazduha je jedan od najvećih problema u Kini tako da grad ima plan da se putem senzora na smart telefonima koristi aplikacija kako bi se videlo gde je najveće zagađenje vazduha u gradu. Osim ovog problema, Peking se suočava sa još mnogim izazovima kao pametan grad kao što je rast urbanizma, unapređenje zdravstvenog sektora, unapređenje sektora edukacije i tako dalje.

Što se tiče Evrope, veliki broj gradova koje se nalaze u okviru država Evropske Unije predstavljaju pametne, a ujedno i brend gradove (Madrid, Barselona, Pariz, Rim, Minhen, Kopenhagen, Amsterdam, Oslo, Moskva, i tako dalje). Evropska Unija je formirala strategiju $E \mathbf{E}$ rope 2020 za podsticanje razvoja i kreiranje poslova u određenim područjima kako bi se kreirala pametna i održiva ekonomija. Ciljevi koji bi trebalo da se dostignu se tiču povećanja zaposlenosti, smanjenja siromaštva u određenim gradovima, zaštita životne energije, edukacija i socijalizacija stanovništva u određenim evropskim gradovima.
Razvoj pametnih gradova se može smatrati korisnim „alatom" kako bi se ciljevi koji su zadati putem strategije Europe 2020 ispunili. Pametni gradovi su ujedno i brend gradovi u kojima se na uspešan način rešavaju problemi na razne teme, kao što su klimatske promene i zagađenje životne sredine. Rezultati mogu biti veoma vidljivi kod velikih gradova. Ono što je potrebno uraditi jeste aktivirati i manje evropske gradove i uključiti ih u proces oživljavanja pametnog i brend grada kako bi se rešavali problemi siromaštva i nezaposlenosti.

Gradovi kao što su Kopenhagen (Danska), Mančester (UK), Barselona (Španija), Amsterdam (Holandija) i Dablin (Irska) su gradovi koji pokrivaju sve karakteristike, tj. postižu sve ciljeve propisani strategijom Europe 2020. Kopenhagen je grad koji se najviše bazira na zaštiti životne sredine, mnogo više nego na ekonomske i političke faktore u zemlji. Amsterdam je jedan od gradova koji se bazira na zaposlenost i inovacije. Barselona je grad koji se najviše bazira na obrazovanje, dok se Dablin, isto kao i Kopenhagen, najviše bazira na održivost životne sredine i na brigu o zagađenju životne sredine [16].

Kada govorimo o američkom tržištu, pojam pametnog grada se odnosi na grad koji koriste visoku tehnologiju u oblasti informatike i komunikacije kako bi postao ,inteligentiji“ u smislu rasporede resursa i smanjivanja troškova i energije. Tehnologije se koriste kako bi se poboljšao kvalitet života američkih građana, kao i kako bi se smanjili negativni efekti zagađivanja životne sredine. Najznačajniji američki pametni gradovi su [17]:

1. Boston, Massachusetts. Boston je grad koji koriste politiku očuvanja energije i životne sredine. Najviše investicija upravo odlazi na tehnologiju kako bi se sačuvala životna sredina.

2. San Jose, California. San Hose predstavlja deo Silikonske doline u Kaliforniji koji takođe koristi „čistu“ tehnologiju. Veliki broj investicija je uloženo u grad kako bi se koristila ,,čista“ tehnologija koja podrazumeva da kompanije proizvode proizvode koji ne štete životnoj sredini.

3. San Diego, California. San Dijego je grad koji, osim što koristi tehnologiju za očuvanje životne sredine, predstavlja i grad koji ima veliki broj kulturno-istorijskih znamenitosti. Proizvod koji se koristi u ovom gradu za postizanje ciljeva očuvanja životne sredine je CleanTECH.

4. Austin, Texas. Ostin je grad koji je poznat po solarnoj energiji, energiji vetra i geotermalnim izvorima. Najveće tehnološke kompanije, kao 
što su HelioVolt, Xtreme Power, i Green Mountain Energy se uprave nalaze u Ostinu.Veliki broj istraživanja na temu održive energije se vrši na Teksas Univerzitetu u Ostinu i od strane koledža prirodnih nauka.

5. Seattle, Washington. Sijetl je grad koji vodi računa o ,zelenim standardima“. Grad je formirao projekat The Green Building Sustainable Communities Program kako bi se grad što bolje upoznao sa važnošću sprečavanja zagađivanja životne sredine.

6. Portland, OR. Portlend je još jedan od gradova koji se visoko rangira kao pametni grad. Još od početka devedesetih godina ovaj američki grad vodi računa o održivosti prirodnih resursa i energije. Portland je grad broj jedan za bicikliste, $\mathrm{u}$ kojem se sve manje koriste druga prevozna sredstva.

7. Chicago, Illinois. Čikago je jedanod gradova u kojem vlade uspevaju da povećavaju stopu zaposlenosti iz godine u godinu tako što se kreira program očuvanja $\mathrm{CO} 2$ emisije. Veliki broj kompanija koristi „,̌istu“ visoku tehnologiju za očuvanje životne sredine kao što su G-Tech Energy Inc. i SoCore Energy.

8. Berkeley, California. Berkli predstavlja grad koji je izgrađen takođe na korišćenju „čiste“ tehnologije gde se koristi gorivo biljnog porekla. To podrazumeva da se koriste određene biljke za proizvodnju goriva kao što su alge ili kukuruz.

9. Washington D.C. Kao glavni grad Amerike, Vašington predstavlja vodeći pametni grad koji koristi ,čistu“ tehnologiju. Vašington je centar svih asocijacija vezanih za održavanje životne sredine kao što su American Wind Association, i American Council on Renewable Energy, the Renewable Energy Incentive Program, i the Renewable Energy Policy Project i tako dalje.

10. San Francisco, California. Pored Vašingtona, još jedan vodeći grad u korišćenju ,čiste“ energije i tehnologije jeste San Francisko. San Francisko predstavlja jedini grad koji će do 2020. godine u potpunosti koristiti obnovljivu energiju. Jedan od najvećih projekata je Sunset Reservoir Solar Project za koji se smatra da će biti gotovo do 2020 . godine.

\section{ZAKLJUČAK}

Savremene ekonomije sve intenzivnije postaju digitalne, dok se istovremeno pred razvojem informacionih i telekomunikacionih tehnologija javljaju novi izazovi koji postavljaju drugačiju dinamiku odnosa svih učesnika na tržištu. Nastanak digitalnih tržišta i ekonomija su upravo dovele do razvoja pametnih gradova koji su istovremeno i brend gradovi a koji ostvaruju višestruke koristi (društvene, ekonomske, turističke, itd.). Zaključuje se da brend gradovi, u isto vreme mogu biti i pametni gradovi koji pametno koriste visoku tehnologiju, intelektualni kapital za razvoja grada, formiranje njegovog imidža, za ekonomski razvoj, infrastrukturu i kulturnoistorijske sadržaje i manifestacije a sve u funkciji boljeg pozicioniranja grada na globalnom tržištu.

Digitalizacija je dovela do nastanka velikog broja aplikacija, koje omogućavaju svim učesnicima na tržišu da uspešnije obavljaju svoje poslovanje, državama da efikasnije komuniciraju sa stanovništvom, kompanijama da posluju sa potrošačima i individualnim korisnicima za kreiranje sopstvenog biznisa.

\section{LITERATURA}

[1] B. Đorđević, Odnosi s potrošačima u digitalnoj ekonomiji. Ekonomski anali, 2007, Vol. 173., Br. 1.

[2] A. Trbović, N. Savić, Z Kukić. Obrazovanje programera i razvoj digitalne ekonomije u Srbiji, Ekonomika preduzeća, vol. 65, br. 1-2, str. 143-154.

[3] F. Grubišić. Geospatial Science and Techology towards a Sustainable Future and Development, Ekscentar, No.17 Lipanj 2014., str. 77-81.

[4] N. K. Aksentijević, Z. Ježić. K. Đurić. Upravljanje ljudskim potencijalima kao pretpostavka inovativnosti i uspješnosti poslovanja Informatologia, 2008, Vol. 41., Br. 1., str. 46-50.

[5] D. MacMillan, P. Burrows, S. E. Ante. Inside the app economy. Business Week, 2009, 22., p. 1-6.

[6] ICT. Regulatory challenges and opportunities in the new ICT ecosystem, Regulatory and Market Enviroment, Telecommunication Development Sector, 2018. p. 1-82; https://www.itu.int/dms_pub/itu-d/ opb/pref/D-PREF-BB.REG_OUT03-2018-PDF-E. pdf

[7] C. W. Cheng. The System and Self-Reference of the app economy: The Case of Angry Birds, Westminster Papers in Communication \& Culture, 2012, 9(1)., p, 47-66; 
[8] M. Szczepański. European app economy State of play, challenges and EU policy, EPRS | European Parliamentary Research Service, 2018, p- 1-8; http://www.europarl.europa.eu/RegData/etudes/BRIE/2018/621894/ EPRS_BRI(2018)621894_EN.pdf

[9] M. Mandel. Korea's App Economy, Progressive Policy Institute May 2018, 2018. Washington, DC, p. 1-12.

[10] M. Mandel, J. Scherer The geography of the app economy. CTIA: The Wireless Association, 2012., p. 1-34.

[11] J. Godfrey, C. Bernard, N. Miller. State of the App Economy, 4th edition, ACT - The App Association, 2016.

[12] E. Long, M. Mandel. Chile: The Road to the App Economy, Progressive Policy Institute April, Washington, DC, 2018, p. 1-11., http://www.progressivepolicy.org/wp-content/uploads/2018/04/PPI_ChileAppEconomy_2018.pdf
[13] R. Stephens, A. Mahesh. State of the App Economy, 6th edition, ACT - The App Association, 2018. https://actonline.org/wp-content/uploads/ ACT_2018-State-of-the-App-Economy-Report_4. pdf

[14] M. Gasco-Hernandez. Building a Smart City: Lessons from Barcelona, Communications of the ACM, 2018, Vol. 61., Br. 4., str., 50-57..

[15] https://www2.deloitte.com/content/dam/Deloitte/ tr/Documents/public-sector/deloitte-nl-ps-smartcities-report.pdf, preuzeto dana 17.02.2019.

[16] C. Manville et al. Mapping smart cities in Europe, Directorate General for internal policies, Policy Department A: Economic and Scientific policy, study, Eurpoean Parlament, 2018.

[17] http://cleantechies.com/2012/03/07/top-ten-unitedstates-smart-cities/, preuzeto dana 17.02.2019.

[18] Smart Cities: Digital Solutions for a More Livable Future, McKinsey Global Insitute, McKinsey \&Company, June 2018. 